\title{
Feasibility of Posterior Cervical Foraminotomy for Adjacent Segmental Disease after Anterior Cervical Fusion
}

\author{
Hyun Jun Kim, Min Soo Kang, ${ }^{1}$ Sang Ho Lee, ${ }^{2}$ Chan Hong Park, ${ }^{3}$ Seok Won Chung, ${ }^{1}$ Yong Hwan Shin, ${ }^{1}$ Shin Young Lee, \\ Eun Soo Park' \\ Department of Neurosurgery, Daegu Wooridul Spine Hospital, Daegu, Korea \\ Department of Neurosurgery, ${ }^{2}$ Wooridul Spine Hospital, Seoul, Korea \\ Department of Anesthesiology and Pain Medicine, ${ }^{3}$ Daegu Wooridul Spine Hospital, Daegu, Korea
}

Objective : The aim of this study is to evaluate the feasibility of posterior cervical foraminotomy (PCF) for adjacent segmental disease (ASD) after anterior cervical fusion (ACF). As ACF is accepted as the standard treatment for cervical spondylosis, many studies have been conducted to evaluate the efficacy of various surgical techniques to overcome symptomatic ASD after the previous surgery. Herein, PCF was performed for the treatment of symptomatic ASD and the feasibility of the surgery was evaluated.

Methods : Forty nine patients who underwent PCF due to symptomatic ASD from August 2008 to November 2017 were identified. For demographic and perioperative data, the sex, age, types of previous surgery, ASD levels, operation times, and bleeding amount were recorded. The clinical outcome was assessed using the visual analogue scale for the neck and arm, the modified Odom's criteria as well as neck disability index. Radiologic evaluations were performed by measuring disc softness, disc height, the cervical 2-7 sagittal vertical axis, cervical cobb angle, and facet violation.

Results : Thirty-seven patients were enrolled in this study. The patients were divided into two groups based on the location of the pathology; paracentral (group P) or foramina (group F). Both groups showed significant clinical improvement $(p<0.05)$. The proportion of calcified disc and facet violations was significantly larger in group $\mathrm{F}(p<0.05)$. The minimal disc height decrease with mild improvement on sagittal alignment and cervical lordosis was radiologically measured without statistical significance in both groups $(p>0.05)$.

Conclusion : PCF showed satisfactory clinical and radiologic outcomes for both paracentral and foraminal pathologies of ASD after ACF. Complications related to anterior revision were also avoided. PCF can be considered a feasible and safe surgical option for ASD after ACF.

Key Words : Minimaly invasive surgery $\cdot$ Revision surgery $\cdot$ Foraminotomy $\cdot$ Radiculopathy.

\section{INTRODUCTION}

Anterior cervical fusion (ACF) is widely accepted as the standard treatment option for cervical spondylosis with radiculopathy or myelopathy. Anterior cervical discectomy and fusion (ACDF) with or without fixation, cervical disc replace-

- Received : February 8, 2020 •Revised : March 11, 2020 •Accepted : March 19, 2020

- Address for reprints : Min Soo Kang

Department of Neurosurgery, Daegu Wooridul Spine Hospital, 648 Gukchaebosang-ro, Jung-gu, Daegu 41939, Korea

Tel : +82-53-212-3000, Fax : +82-53-212-3049, E-mail : mansiki@hanmail.net, ORCID : https://orcid.org/0000-0002-8698-7963

This is an Open Access article distributed under the terms of the Creative Commons Attribution Non-Commercial License (http://creativecommons.org/licenses/by-nc/4.0) which permits unrestricted non-commercial use, distribution, and reproduction in any medium, provided the original work is properly cited. 
ment (CDR), and anterior cervical corpectomy and fusion (ACCF) are representative surgical techniques in this category. Although ACF provides direct decompression at the index level, the surgical technique affects the kinetics of adjacent levels, facilitating degenerative changes on those levels ${ }^{13)}$. Adjacent segment disease (ASD) is a disease that can develop either iatrogenically after ACF or through the natural progression of degenerative changes ${ }^{22)}$. The incidence of ASD is reported to range from $2.1 \%$ to $22 \%$ and most cases are asymptomatic ${ }^{21)}$. However, surgical treatment should be considered for ASD that cannot be relieved with conservative treatment or procedures ${ }^{9)}$. Hilibrand et al. ${ }^{9)}$ reported that two-thirds of patients in this category may require secondary surgery.

A variety of approaches and surgical techniques are available for the treatment of ASD after ACF. Reported techniques for ASD after ACF include repeat ACDF, ACDF with a zeroprofile device, CDR, and laminoplasty ${ }^{3,14,16,18,22)}$. All of these techniques have shown good clinical results, with Wang et $\mathrm{al}^{22)}$ reporting a lower incidence of dysphagia in the zero-profile group. Although ASD occurs at the level above or below the level of the previous operation, adhesive tissue and scars from the previous surgery are likely to exist in the anterior corridor. This can increase the difficulty of performing a secondary operation and predispose patients to complications related to vital organs in the anterior neck region such as the trachea, esophagus, recurrent laryngeal nerve, and carotid sheath. In contrast, the posterior approach provides access to virgin tissue; hence, damage to vital organs can be avoided. Laminectomy with internal fixation and laminoplasty have been reported as posterior approach techniques for ASD after $\mathrm{ACF}^{22)}$. However, posterior cervical foraminotomy (PCF) as a surgical option has never been reported. PCF is appropriate for posterolateral soft disc herniation or cervical foraminal stenosis due to osteophytosis or hypertrophy of the facet joint $^{10)}$. The procedure can preserve the range of motion (ROM) at the index segment with a minimal decrease in disc height (DH). It may also improve sagittal alignment and the lordotic angle in addition to preserving the ROM in select cas$\mathrm{es}^{5,12)}$. In this study, PCF was performed for ASD after ACF and the clinical and radiological outcomes were assessed. The location of the pathology was also taken into consideration to determine the appropriate surgical option. Foraminal or extra-foraminal stenosis and disc extrusion are risk factors for facet joint violation; therefore, ACF is widely accepted as a standard treatment option for such cases ${ }^{17)}$. However, massive facet violation during PCF can be avoided by widening the vertical width during foraminotomy with inferior lamina resection, making PCF a viable option for these types of pathologies $^{2}$. To evaluate the feasibility of this approach, the study population was divided into two groups, namely the paracentral (group P) and foraminal (group F), based on the location of the pathology and the clinical and radiologic outcomes in the two groups were compared.

\section{MATERIALS AND METHODS}

The study was approved by the Institutional Review Board of Wooridul Spine Hospital, and all patients gave informed consent before enrollment.

\section{Patient population, indications, and inclusion cri- teria}

Fifty-four patients that required repeat cervical surgery due to symptomatic ASD from August 2008 to November 2017 were identified. All patients failed to improve after more than 6 weeks of conservative management and developed new radiologic degenerative changes at adjacent levels. Forty-nine patients presented only unilateral radiculopathy without myelopathy, but five patients also suffered from neck pain with myelopathic symptoms. The indication for PCF was unilateral radiculopathy without myelopathy, posterior neck pain, or focal dynamic instability. Focal dynamic instability was defined as a translation of more than $3.5 \mathrm{~mm}$ and angulation exceeding $11^{\circ}$ in sagittal dynamic plain radiographs ${ }^{5}$. Five patients with myelopathy, posterior neck pain, and focal dynamic instability on adjacent levels were excluded as they had undergone revisional ACDF. Therefore, PCF was performed for 49 patients.

Patients who underwent PCF less than a year after the previous surgery or at a level distant from the prior surgery were also excluded. Complete data with 1 year of medical and radiologic follow-up were available for 37 patients. Four patients were excluded from this study because PCF was performed within a week after the previous surgery due to incomplete decompression or sustained radiculopathy. Five patients underwent surgery at locations distant from the original operated level. Three patients were lost before the 1-year follow-up. Consequently, 12 out of 49 patients were excluded and 37 pa- 
tients were enrolled in this study.

\section{Surgical technique}

All patients underwent surgery in the prone position under general anesthesia. After confirmation of the cervical level using a lateral X-ray, a $3 \mathrm{~cm}$ vertical skin incision was made and routine muscular dissection was performed to expose the lamina and facet. A semi-tubular retractor (Papavero-Caspar speculum; B Braun, Melsungen, Germany) was used. Target level confirmation was achieved by checking the lateral X-ray with a micro-surgical probe placed on the targeted lamina. Open microscopic laminotomy and foraminotomy with partial facetectomy were performed using high-speed drills. The medio-lateral course of the nerve root was exposed. If tension on the nerve root remained after foraminotomy, additional bony decompression of the inferior pedicle with a $3 \mathrm{~mm}$ diamond burr was performed for patients with foraminal stenosis with calcified discs or traction spurs. For soft disc extrusion cases, additional decompression was performed by discectomy with pituitary forceps. After surgery, patients were placed in a soft collar for 2-4 weeks.

\section{Demographics}

Demographic data was collected from the patients' medical charts. The operated levels, sex, age, type of previous surgery, affected level, relationship of affected levels to the operated levels, interval between first and second operation, and duration of symptoms were recorded as the demographic data. The perioperative data were collected from a review of the patients' medical charts and operation records. For perioperative data, the operation time, bleeding amount, number of admission days, and complication types were recorded.

\section{Clinical outcomes}

Patients were asked by the surgeon to rate their neck and arm pain intensity using the visual analogue scale (VAS) at three time points : prior to operation, postoperative day (POD) 1, and at the 1-year follow-up outpatient visit. Odom's criteria and the neck disability index (NDI) were applied based on the subjective symptoms and working capacity at POD 1 and at the 1-year follow-up. The data were collected from pre and postoperative medical charts or telephone interviews.

\section{Radiologic outcomes}

The disc location, disc softness, DH, C2-7 sagittal vertical axis (C2-7 SVA), cervical Cobb angle (CA), and facet violation ratio were measured from the preoperation, POD 1, and 1-year follow-up plain cervical radiographs (X-ray), computerized tomography $(\mathrm{CT})$ images, and magnetic resonance imaging (MRI) data. The preoperative ROM for the affected level was measured to exclude focal dynamic instability. The angle be-
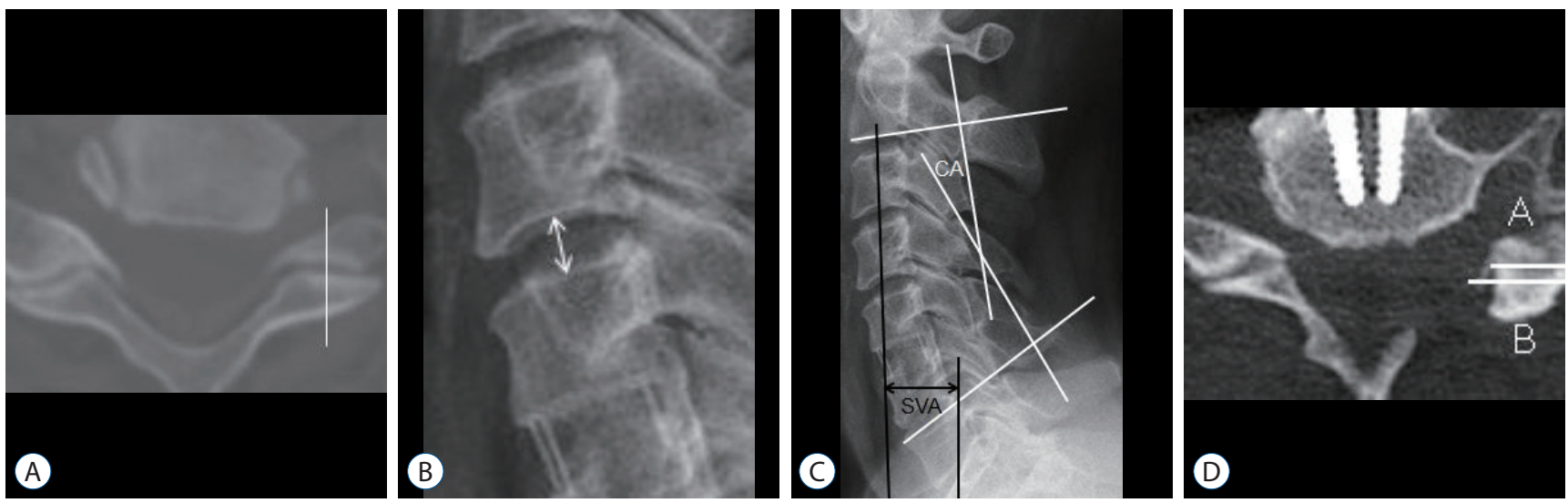

Fig. 1. A : The white line is the midline of the facet joint. Pathology across this line was categorized as paracentral while that outside the line was categorized as foraminal. B : Double headed arrow indicates the disc height. It was measured as the length from the midpoint of the upper endplate of the lower vertebral body to the midpoint of the lower endplate of the upper vertebral body. C : The C2-7 sagittal vertical axis (SVA) was measured as the length from the vertical line starting at the center of the C2 vertebral body (vertical black line) to the end point of the superior posterior of the C7 vertebral body (horizontal black line). The cervical Cobb angle (CA) was measured as the angle between two lines parallel to the lower margin of the $\mathrm{C} 2$ vertebral body and the upper margin of the $\mathrm{C} 7$ vertebral body (white lines). $D$ : The amount of facet resection was measured as the proportion of resected facet ( $A$, white line) compared to the original facet ( $B$, white line). The formula was (A-B) / A $\times 100$. 
tween the superior endplate of the upper vertebra and the lower endplate of the lower vertebra was defined as the ROM and was measured from flexion and extension images using Cobb' $s$ method. Discs located medial to the midpoint of the facet were placed in the paracentral group (group P), and those lateral to the midpoint of the facet were placed in the foraminal group (group F) (Fig. 1A). Disc softness was classified as soft, calcified, or mixed based on the density of the CT image. Discs with Hounsfield units similar to that of the cortical bone of the vertebral body were defined as calcified discs. The $\mathrm{DH}$ was measured from the midpoint of the upper endplate of the lower vertebral body to the midpoint of the lower endplate of the upper vertebral body (Fig. 1B). The DH was the average value from the X-ray, CT, and MRI results. C2-7 SVA was measured from lateral cervical X-ray images as the distance between the vertical line at the center of the $\mathrm{C} 2$ vertebral body and the vertebral line at the superior posterior of the $\mathrm{C} 7$ vertebral body (Fig. 1C). CA was measured to evaluate the change in the overall cervical sagittal alignment. Two spinal neurosurgeons individually measured the CA between C2 and C7, which was defined as the angle formed by lines drawn at the base of the axis and the superior endplate of the $\mathrm{C} 7$ vertebral body on the lateral radiograph. The mean angle was calculated to accommodate investigator error in assessing the margins of the vertebral bodies (Fig. 1C) ${ }^{5}$. Kyphotic alignment was indicated as a negative value and lordotic alignment was indicated as a positive value. The percentage of the facet joint removed was measured as the ratio of the horizontal length of the original facet joint (A) and the horizontal length of the remaining facet joint (B). The formula for this calculation was $[(A-B) / A] \times 100$. $(\text { Fig. } 1 D)^{6}$. Measurements were quantified using features included in a picture archiving communication system (PACS; PiViewSTAR; INFINITT Healthcare Co, Seoul, Korea). All radiologic data were measured by each operator, the first author, and the corresponding author of this article. The measurements of the three investigators had an intra-class correlation of $93.2 \%$ with statistical significance ( $p=0.000)$. The mean value of the three measurements was obtained to further adjust the errors between the investigators.

\section{Statistics}

Statistical comparison of the clinical and radiological outcomes was made between groups P and F. An independent sample t-test was used to compare variables with average values and the chi-squared test was used for categorical values between the two groups. A paired t-test was used to compare variables with average values between preoperation and the 1-year follow-up within each group. Statistical analysis was performed using standard software (SPSS ver. 16.0 for Windows; SPSS, Inc, Chicago, IL, USA) and statistical significance was set at $p<0.05$.

Table 1. Demographics

\begin{tabular}{|c|c|}
\hline Variable & Value \\
\hline \multicolumn{2}{|l|}{ Sex } \\
\hline Male & $29(78.4)$ \\
\hline Female & $8(21.6)$ \\
\hline Age (years) & $51.70 \pm 9.70$ \\
\hline \multicolumn{2}{|l|}{ Types of previous surgery } \\
\hline ACDF & $20(54.0)$ \\
\hline ACDF, stand alone & $12(32.4)$ \\
\hline CDR & $3(8.1)$ \\
\hline ACCF & $2(5.5)$ \\
\hline \multicolumn{2}{|l|}{ Affected level } \\
\hline C $3-4$ & $2(5.5)$ \\
\hline C4-5 & $6(16.2)$ \\
\hline C5-6 & 7 (21.6) \\
\hline C6-7 & $15(40.5)$ \\
\hline $\mathrm{C} 7-\mathrm{T} 1$ & $6(16.2)$ \\
\hline \multicolumn{2}{|l|}{ Relationship of affected levels } \\
\hline Upper & $10(27.0)$ \\
\hline Index & $7(19.0)$ \\
\hline Lower & $20(54.0)$ \\
\hline Interval between 1st and 2nd operation (months) & $67.70 \pm 54.97$ \\
\hline Duration of symptoms (weeks) & $11.46 \pm 20.78$ \\
\hline Foraminotomy with discectomy & $5(13.5)$ \\
\hline Operation times (minutes) & $115.22 \pm 46.30$ \\
\hline Bleeding amount $(\mathrm{mL})$ & $202.57 \pm 105.08$ \\
\hline Admission period (days) & $18.67 \pm 29.84$ \\
\hline \multicolumn{2}{|l|}{ Complications } \\
\hline CSF leakage & $2(5.5)$ \\
\hline Wound dehiscence & $1(2.7)$ \\
\hline Wound infection & $1(2.7)$ \\
\hline
\end{tabular}




\section{RESULTS}

\section{Demographics}

As shown in Table 1, ASD after ACF showed male predominance in this study $(29,78.4 \%)$. The average age of the patients

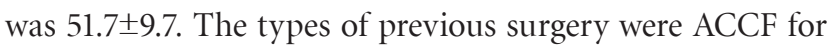
two patients (5.5\%), ACDF for 20 patients (54\%), ACDF with a stand-alone cage for 12 patients (32.4\%), and CDR for three patients (8.1\%). The affected levels were as follows : C3-4 for two patients (5.5\%), C4-5 for six patients (16.2\%), C5-6 for eight patients (21.6\%), C $6-7$ for 15 patients (40.5\%), and C7$\mathrm{T} 1$ for six patients (16.2\%). The affected levels were above the operated level in 10 patients (27\%), below the operated level in
20 patients (54\%), and the same as the operated level in seven patients (19\%). The interval between the first and second operations was $67.70 \pm 54.97$ months and the symptom duration before the second operation was $11.46 \pm 20.78$ weeks. Foraminotomy with discectomy was performed in five cases (13.5\%) and sufficient decompression was achieved without discectomy for the other 32 patients $(86.5 \%)$. The operation time was $115.22 \pm 46.30$ minutes and the bleeding amount was 202.57 \pm $105 \mathrm{~mL}$. The average number of admission days was 18.67 \pm 29.84 days for all patients but was $9.75 \pm 29.06$ days for patients without complications. Thirty-three patients (89.1\%) did not experience any complications but there were two cases of wound dehiscence $(5.5 \%)$, one case of wound infection $(2.7 \%)$,

Table 2. Clinical outcomes

\begin{tabular}{|c|c|c|c|c|c|}
\hline Variable & Group P $(n=14)$ & $\begin{array}{l}\text { Within group } \\
\text { difference } \\
\text { (preopertion to } \\
12 \text { months) }\end{array}$ & Group F $(n=23)$ & $\begin{array}{l}\text { Within group } \\
\text { difference } \\
\text { (preopertion to } \\
12 \text { months) }\end{array}$ & $\begin{array}{l}p \text {-value of between } \\
\text { group differences }\end{array}$ \\
\hline VAS arm & & $6.05 ; p=0.000$ & & $6.07 ; p=0.000$ & \\
\hline Preoperation & $8.76 \pm 0.83$ & & $8.79 \pm 0.77$ & & 0.907 \\
\hline Postoperation & $2.76 \pm 0.83$ & & $3.03 \pm 0.56$ & & 0.211 \\
\hline 12 months f/u & $2.71 \pm 0.69$ & & $2.72 \pm 0.88$ & & 0.942 \\
\hline VAS neck & & $3.37 ; p=0.000$ & & $3.14 ; p=0.000$ & \\
\hline Preoperation & $6.13 \pm 0.60$ & & $5.71 \pm 0.73$ & & 0.128 \\
\hline Postoperation & $2.76 \pm 0.75$ & & $2.67 \pm 0.50$ & & 0.336 \\
\hline 12 months f/u & $2.65 \pm 0.65$ & & $2.57 \pm 0.51$ & & 0.765 \\
\hline NDI (\%) & & $20.3 ; p=0.000$ & & $21.3 ; p=0.000$ & \\
\hline Preoperation & $30.91 \pm 4.78$ & & $30.93 \pm 3.77$ & & 0.755 \\
\hline Postoperation & $11.0 \pm 5.42$ & & $10.9 \pm 4.22$ & & 0.884 \\
\hline 12 months f/u & $10.43 \pm 1.47$ & & $10.14 \pm 2.60$ & & 0.903 \\
\hline \multicolumn{6}{|l|}{ Odom's criteria (\%) } \\
\hline Postoperation & & $\mathrm{N} / \mathrm{A}$ & & N/A & 0.436 \\
\hline Excellent & $3(21.5)$ & & $5(21.7)$ & & \\
\hline Good & $11(78.5)$ & & 15 (65.2) & & \\
\hline Fair & $0(0.0)$ & & 2 (8.6) & & \\
\hline Poor & $0(0.0)$ & & $1(4.5)$ & & \\
\hline 12 months f/u & & N/A & & N/A & 0.263 \\
\hline Excellent & $3(21.5)$ & & 8 (34.8) & & \\
\hline Good & $10(71.4)$ & & $10(43.5)$ & & \\
\hline Fair & $1(7.1)$ & & $4(17.2)$ & & \\
\hline Poor & $0(0.0)$ & & $1(4.5)$ & & \\
\hline
\end{tabular}

Values are presented as mean \pm standard deviation or number (\%). P : paracentral, F : foraminal, VAS : visual analogue scale, f/u : follow up, NDI : neck disability index, N/A : not applicable 
and one case of cerebrospinal fluid leakage (2.7\%).

\section{Clinical outcomes}

The mean follow-up period was 18.5 months, ranging from 13 to 47 months. Patients were divided into two groups based on the location of the pathology that caused the radiculopathy : 14 patients were in group $\mathrm{P}$ and 23 were in group F. The clinical outcomes for both groups are summarized in Table 2. The mean VAS for arm pain improved from $8.76 \pm 0.83$ to $2.76 \pm$ 0.83 in group $P$ and from $8.79 \pm 0.77$ to $3.03 \pm 0.56$ in group $F$. The mean VAS for neck pain improved from $6.13 \pm 0.60$ to 2.76 \pm 0.75 in group $P$ and from $5.71 \pm 0.73$ to $2.57 \pm 0.50$ in group $F$. The improvement persisted until the 1-year follow-up in both groups without significant change. The mean NDI improved from $30.91 \pm 4.78$ to $11.0 \pm 5.42$ in group P and from $30.93 \pm 3.77$ to $10.9 \pm 4.22$ in group F. In terms of VAS arm, neck and NDI, there was a significant within-group difference between preoperation and 12 months follow-up $(p<0.05)$. The improve- ment also persisted until the 1-year follow-up in both groups. Based on Odom's criteria, three patients (21.5\%) in group P and five patients (21.7\%) in group F were rated as excellent (Odom I), while 11 patients (78.5\%) in group P and 15 patients $(65.2 \%)$ in group F were rated as good (Odom II). None of the patients in group $\mathrm{P}$ were rated as Odom III or IV, but two patients $(8.6 \%)$ in group F were rated as Odom III and one patient $(4.5 \%)$ was rated as Odom IV. The proportion of patients rated as Odom I and II remained constant until the 1-year follow-up visit. There were no significant statistical differences in the clinical outcomes between the two groups and the outcomes after surgery were satisfactory in both groups.

\section{Radiologic outcomes}

The radiologic outcomes are summarized in Table 3. The preoperative ROM at the affected level was $9.78 \pm 3.45^{\circ}$ in group $\mathrm{P}$ and $9.34 \pm 2.32^{\circ}$ in group F and there was no significant difference statistically. These values indicated both

Table 3. Radiologic outcomes

\begin{tabular}{|c|c|c|c|c|c|}
\hline Variable & Group $P(n=14)$ & $\begin{array}{l}\text { Within group } \\
\text { difference } \\
\text { (preopertion to } \\
12 \text { months) }\end{array}$ & Group $F(n=23)$ & $\begin{array}{l}\text { Within group } \\
\text { difference } \\
\text { (preopertion to } \\
12 \text { months) }\end{array}$ & $\begin{array}{l}p \text {-value of between } \\
\text { group differences }\end{array}$ \\
\hline Preoperative ROM of affected level $\left(^{\circ}\right)$ & $9.78 \pm 3.45$ & N/A & $9.34 \pm 2.32$ & $\mathrm{~N} / \mathrm{A}$ & 0.603 \\
\hline Disc softness (\%) & & N/A & & N/A & 0.003 \\
\hline Soft & $12(82.6)$ & & $5(21.7)$ & & \\
\hline Calcified & $1(7.2)$ & & $15(65.2)$ & & \\
\hline Mixed & $1(7.2)$ & & $3(13.1)$ & & \\
\hline Disc height (mm) & & $0.27 ; p=0.093$ & & $0.31 ; p=0.081$ & \\
\hline Preoperation & $7.01 \pm 1.49$ & & $6.36 \pm 1.48$ & & 0.158 \\
\hline Postoperation & $6.86 \pm 1.59$ & & $6.19 \pm 1.38$ & & 0.140 \\
\hline 12 months f/u & $6.74 \pm 1.56$ & & $6.05 \pm 1.34$ & & 0.119 \\
\hline Cervical 2-7 Sagittal vertical axis (mm) & & $2.19 ; p=0.427$ & & $1.95 ; p=0.475$ & \\
\hline Preoperation & $20.62 \pm 13.77$ & & $23.14 \pm 12.27$ & & 0.523 \\
\hline Postoperation & $18.43 \pm 11.60$ & & $21.09 \pm 10.60$ & & 0.098 \\
\hline 12 months f/u & $18.98 \pm 12.09$ & & $21.19 \pm 10.09$ & & 0.095 \\
\hline Cervical Cobb angle $\left(^{\circ}\right)$ & & $5.74 ; p=0.083$ & & $4.52 ; p=0.178$ & \\
\hline Preoperation & $3.14 \pm 12.58$ & & $3.59 \pm 11.73$ & & 0.904 \\
\hline Postoperation & $7.56 \pm 11.13$ & & $7.29 \pm 11.69$ & & 0.939 \\
\hline 12 months f/u & $8.88 \pm 11.43$ & & $8.11 \pm 9.37$ & & 0.810 \\
\hline Facet violation (\%) & $29 \pm 0.09$ & N/A & $44 \pm 0.10$ & N/A & 0.000 \\
\hline
\end{tabular}

Values are presented as mean \pm standard deviation or number (\%). P : paracentral, F : foraminal, ROM : range of motion, N/A : not applicable, f/u : follow up 
groups had ROM restrictions without focal dynamic instability. The majority of patients $(12,85.6 \%)$ in group $\mathrm{P}$ had soft disc herniation, whereas most $(15,65.2 \%)$ group F patients had stenosis with calcified discs or traction spurs. The average Hounsfield unit for calcified discs or traction spurs was 854.23 \pm 113.77 . Statistical differences were also observed between the two groups $(p<0.05)$. The preoperative average $\mathrm{DH}$ was $7.01 \pm$ $1.49 \mathrm{~mm}$ in group $\mathrm{P}$ and $6.36 \pm 1.48 \mathrm{~mm}$ in group $\mathrm{F}$. The postoperative $\mathrm{DH}$ decreased minimally, with an average $\mathrm{DH}$ of $6.86 \pm 1.59 \mathrm{~mm}$ in group $\mathrm{P}$ and $6.19 \pm 1.38$ in group $\mathrm{F}$. DH was maintained without a significant decrease at the 1-year followup in both groups (Fig. 2A). There were no significant within and between group differences. The preoperative C2-7 SVA and CA were $20.62 \pm 13.77 \mathrm{~mm}$ and $3.14 \pm 12.58^{\circ}$, respectively, in group $\mathrm{P}$, and $23.62 \pm 12.27 \mathrm{~mm}$ and $3.59 \pm 11.78^{\circ}$, respectively, in group F. The postoperative C2-7 SVA and CA improved to $16.43 \pm 11.60 \mathrm{~mm}$ and $7.56 \pm 11.13^{\circ}$, respectively, in group $\mathrm{P}$, and to $22.09 \pm 10.60 \mathrm{~mm}$ and $7.29 \pm 11.69^{\circ}$, respectively, in group $\mathrm{F}$. C2-7 SVA and CA remained unchanged at the 1-year followup in both groups (Fig. 2B and C). In terms of C2-7 SVA, and $\mathrm{CA}$, there were no significant within and between group differences. Facet violation was significantly larger in group $\mathrm{F}$ $(p<0.05)$. The mean facet violation was $29 \%$ in group $\mathrm{P}$ and $44 \%$ in group $\mathrm{F}$.

\section{DISCUSSION}

There were some interesting findings in the demographic data for the study population. Firstly, 20 cases (54\%) of ASD occurred at a level below the index segment and 28 cases $(78.3 \%)$ were at the lower cervical area (C6-T1). Previous studies reported that lower segments have greater influence on the cervical $\mathrm{ROM}^{4)}$. Once ACDF is performed, the motion at the index level is fixed and a compensation mechanism is triggered to maintain the cervical ROM. Lin et al. ${ }^{17)}$ reported that the cervical ROM decreases after ACDF, while the ROM at the upper and lower segments increases. They also reported a significant correlation between the ROM for the lower segment and that of the entire cervical region ${ }^{17)}$. The findings in the current study support previous reports indicating the lower segments contribute substantially to the cervical ROM.

Secondly, the previous surgery in 32 cases (86.4\%) was ACDF and 12 (37.5\%) of these were performed using a standalone technique. ACDF is a widely accepted standard surgery for cervical spondylosis; however, recent studies suggest that the ROM at adjacent levels is significantly higher than that obtained with CDR or PCF by fixing the ROM for the index level ${ }^{11,17)}$. Han et al. ${ }^{8)}$ reported that the stand-alone ACDF group showed more frequent segmental subsidence and cervical kyphosis than the conventional ACDF group. The relatively high proportion of stand-alone ACDF in this study could be explained by the combination of these two effects. Additionally, there were seven cases of surgery at the index level, which was likely induced by the progression of foraminal stenosis after incomplete decompression with the previous ACDF. It is difficult to remove pathologies in the most lateral area using the anterior approach because of uncinate processes; therefore, a combined operation involving anterior foraminotomy or uncinate process resection should be considered for pa-
Disc height $(\mathrm{mm})$

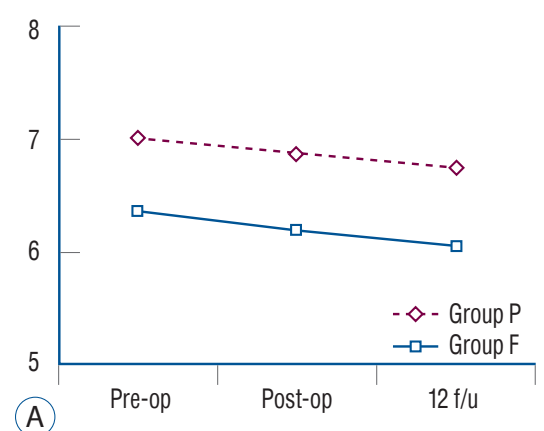

C2-7 sagittal vertical axis ( $\mathrm{mm})$

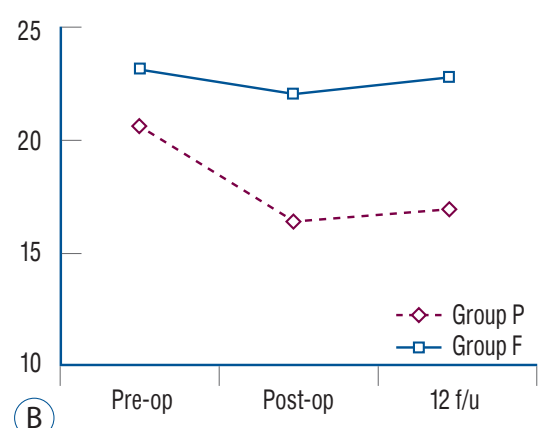

Cervical angle (degree)

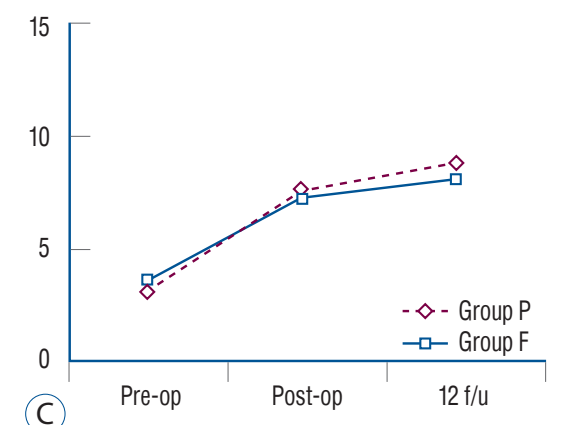

Fig. 2. A : Disc height change with time shows a minimal decrease after posterior cervical foraminotomy (PCF). B : C2-7 sagittal vertical axis change with time shows the improvement of the sagittal alignment after PCF.C: Cervical Cobb angle with time shows mild recovery of cervical lordosis after PCF. Pre-op: preoperation, Post-op: postoperation, $\mathrm{f} / \mathrm{u}$ : follow up. 
tients with foraminal stenosis to avoid secondary surgery ${ }^{6}$.

Performing PCF for ASD after ACF in both the P and F groups resulted in satisfactory clinical and radiologic outcomes in this study and the outcomes persisted 1 year later. Radiologic examinations showed minimal DH decrease with slight recovery of the cervical alignment and lordotic angle as the patients' symptoms were relieved. Kyphotic cervical deformity with malalignment is known as a contraindication for surgery with a posterior cervical approach. However, a report indicated that the deformity could be overestimated because of pain-induced muscle spasms ${ }^{5)}$. Temporal kyphosis and shifted SVA can also be caused by posterior neck pain and muscle spasms; therefore, PCF can be performed for select patients with acute malalignment. Since C2-7 SVA and CA cannot be fixed by mechanical deformity, the alignment and lordotic angle could be improved for such patients ${ }^{5,12,15)}$. Acute onset kyphosis should not be considered as an absolute contraindication.

Group F had a higher facet violation rate (44\%) than group P (29\%) in this study. This is because the pathology was located in a more lateral area in group $\mathrm{F}$ and facetectomy was necessary for complete decompression. Some studies suggest that facet resections greater than 50\% can induce instability; however, existing evidence suggests complete decompression is more important than the avoidance of facet resection as long as the proportion of the violation falls in the range of 25$50 \%{ }^{6,23)}$. There was also no instability observed in this study within 1 year of follow-up, but a longer follow-up period is needed. For patients with diffuse foraminal stenosis, which may invade the facet joint by more than $50 \%$, ACDF is recommended $^{5)}$.

Performing surgery for ASD after ACF through the anterior corridor bears the risk of damaging anterior vital organs. Complications such as dysphagia, dysphonia, and injury to the vertical axis, sympathetic chain, esophagus, and other structures have been reported $^{19)}$. Basques et al. ${ }^{1)}$ reported that there were more thromboembolic events, surgical site infections, and readmission within 30 days in the revision ACDF group. On the other hand, posterior approaches provide access to virgin tissue in the ASD region, thus, complications related to revision anterior-approach surgery can be avoided. In this study, there were no severe complications except for two cases of CSF leakage and one case of wound infection. Total laminectomy with lateral mass fixation or laminoplasty have been reported as surgical options for ASD after ACF that can avoid complications related to anterior organs ${ }^{22)}$. However, these techniques require a wider incision and muscle dissection, consequently damaging the posterior neural arch. This affects not only the postoperative neck pain, but also aggravates postoperative kyphosis. In contrast, PCF can be performed with fewer invasions on the posterior neural arch, less bleeding loss, and a shorter operation time. Furthermore, PCF can preserve the ROM at the operated level, which can prevent further ASD occurrence on levels above or below. However, there are several pitfalls of this technique such as postoperative neck pain, progression of kyphosis, nerve root injury, and difficulty with bleeding control ${ }^{7,10)}$. The procedure is contraindicative for central disc herniation, axial neck pain without radicular symptoms, and patients with dynamic instability ${ }^{20)}$. PCF therefore appears to be a feasible surgical option for ASD after ACF capable of preserving cervical motion and preventing the occurrence of additional ASD.

This study is meaningful as it is the first to analyze PCF as a revision surgery for ASD after anterior-approach cervical surgeries. However, this study is retrospective with a relatively small number of patients and lacked randomization. There is a possibility of selection and recall bias, and generalization of the results of this study should be approached with caution due to the small patient population. A prospective study with a larger number of patients is need to validate the effectiveness of PCF after ASD and a longer follow-up period is needed to confirm the improvement in C2-7 SVA and CA is not temporary.

\section{CONCLUSION}

Minimal invasive microscopic PCF on ASD after ACF showed good clinical and radiologic outcomes for paracentral and foraminal pathologies. The complication rate was also minimal, with no severe complications related to anterior revision. Based on the results of the study, PCF is presented as an effective and safe option for secondary surgery for ASD after ACF.

\section{CONFLICTS OF INTEREST}

No potential conflict of interest relevant to this article was reported. 


\section{INFORMED CONSENT}

Informed consent was obtained from all individual participants included in this study.

\section{AUTHOR CONTRIBUTIONS}

\author{
Conceptualization : HJK, MSK \\ Data curation : HJK, SWC, ESP \\ Formal analysis : HJK, YHS, SYL \\ Funding acquisition : SHL, CHP \\ Methodology : HJK, MSK \\ Project administration : SHL, CHP \\ Visualization : HJK, MSK \\ Writing - original draft : HJK, MSK \\ Writing - review \& editing : HJK, MSK
}

\section{ORCID}

$\begin{array}{ll}\text { Hyun Jun Kim } & \text { https://orcid.org/0000-0002-2489-7524 } \\ \text { Min Soo Kang } & \text { https://orcid.org/0000-0002-8698-7963 } \\ \text { Sang Ho Lee } & \text { https://orcid.org/0000-0002-8526-0260 } \\ \text { Chan Hong Park } & \text { https://orcid.org/0000-0002-1305-0395 } \\ \text { Seok Won Chung } & \text { https://orcid.org/0000-0002-7577-0603 } \\ \text { Yong Hwan Shin } & \text { https://orcid.org/0000-0002-1548-4998 } \\ \text { Shin Young Lee } & \text { https://orcid.org/0000-0002-2765-7665 } \\ \text { Eun Soo Park } & \text { https://orcid.org/0000-0002-1628-5296 }\end{array}$

\section{References}

1. Basques BA, Ondeck NT, Geiger EJ, Samuel AM, Lukasiewicz AM, Webb $M L$, et al. : Differences in short-term outcomes between primary and revision anterior cervical discectomy and fusion. Spine (Phila Pa 1976) 42 : 253-260, 2017

2. Bayoumi AB, Berk S, Efe IE, Bas EG, Duran M, Yigit T, et al. : Posterior cervical keyhole laminoforaminotomy: a cadaveric comparative study to evaluate limits of bony resection. Oper Neurosurg (Hagerstown) 16 : 607-613, 2019

3. Bydon M, Xu R, De la Garza-Ramos R, Macki M, Sciubba DM, Wolinsky $J P$, et al. : Adjacent segment disease after anterior cervical discectomy and fusion: incidence and clinical outcomes of patients requiring anterior versus posterior repeat cervical fusion. Surg Neurol Int 5(Suppl 3) : S74-S78, 2014
4. Cho TG, Kim YB, Park SW : Long term effect on adjacent segment motion after posterior cervical foraminotomy. Korean J Spine 11 : 1-6, 2014

5. Chung SW, Kim HJ, Lee SH, Lee SY, Kang MS, Shin YH, et al. : Posterior cervical foraminotomy for cervical radiculopathy: should cervical alignment be considered? J Spine Surg 5 : 541-548, 2019

6. Gu BS, Park JH, Seong HY, Jung SK, Roh SW : Feasibility of posterior cervical foraminotomy in cervical foraminal stenosis: prediction of surgical outcomes by the foraminal shape on preoperative computed tomography. Spine (Phila Pa 1976) 42 : E267-E271, 2017

7. Guo Q, Wang L, Zhang B, Jiang J, Guo X, Lu X, et al. : Standalone anterior cervical discectomy and fusion versus combination with foraminotomy for the treatment of cervical spondylotic radiculopathy secondary to bony foraminal stenosis. World Neurosurg 95 : 134-142, 2016

8. Han SY, Kim HW, Lee CY, Kim HR, Park DH : Stand-alone cages for anterior cervical fusion: are there no problems? Korean J Spine 13 : 13-19, 2016

9. Hilibrand AS, Carlson GD, Palumbo MA, Jones PK, Bohlman HH : Radiculopathy and myelopathy at segments adjacent to the site of a previous anterior cervical arthrodesis. J Bone Joint Surg Am 81 : 519-528, 1999

10. Kang MS, Choi KC, Lee CD, Shin YH, Hur SM, Lee SH : Effective cervical decompression by the posterior cervical foraminotomy without discectomy. J Spinal Disord Tech 27 : 271-276, 2014

11. Kim KT, Cho DC, Sung JK, Kim YB, Kim DH. Comparative analysis between total disc replacement and posterior foraminotomy for posterolateral soft disc herniation with unilateral radiculopathy : clinical and biomechanical results of a minimum 5 years follow-up. J Korean Neurosurg Soc $60:$ 30-39, 2017

12. Kim SJ, Seo JS, Lee SH, Bae J : Comparison of anterior cervical foraminotomy and posterior cervical foraminotomy for treating single level unilateral cervical radiculopathy. Spine (Phila Pa 1976) 44 : 1339-1347, 2019

13. Kretzer RM, Hsu W, Hu N, Umekoji H, Jallo Gl, McAfee PC, et al. : Adjacent-level range of motion and intradiscal pressure after posterior cervical decompression and fixation: an in vitro human cadaveric model. Spine (Phila Pa 1976) 37 : E778-E785, 2012

14. Lee SB, Cho KS. Cervical arthroplasty versus anterior cervical fusion for symptomatic adjacent segment disease after anterior cervical fusion surgery: review of treatment in 41 patients. Clin Neurol Neurosurg 162 : 59-66, 2017

15. Lee YS, Kim YB, Park SW, Kang DH : Preservation of Motion at the Surgical Level after Minimally Invasive Posterior Cervical Foraminotomy. J Korean Neurosurg Soc 60 : 433-440, 2017

16. Li J, Tong T, Niu R, Shen Y : A study on the clinical outcomes of patients with revision surgery for adjacent segment disease after 10-year's anterior cervical spine surgery. J Orthop Surg Res $11:$ 5, 2016

17. Lin GX, Rui G, Sharma S, Kotheeranurak V, Suen TK, Kim JS : Does the neck pain, function, or range of motion differ after anterior cervical fusion, cervical disc replacement, and posterior cervical foraminotomy? World Neurosurg 129 : e485-e493, 2019 
18. Lu VM, Mobbs RJ, Phan K : Clinical outcomes of treating cervical adjacent segment disease by anterior cervical discectomy and fusion versus total disc replacement: a systematic review and meta-analysis. Global Spine J 9 : 559-567, 2019

19. Lubelski $D$, Healy AT, Silverstein MP, Abdullah $K G$, Thompson NR, Riew $K D$, et al. : Reoperation rates after anterior cervical discectomy and fusion versus posterior cervical foraminotomy: a propensity-matched analysis. Spine J 15 : 1277-1283, 2015

20. Ryan J, McGowan JE, Voyadzis JM : Treating cervical radiculopathy for a one-level disc herniation using a posterior foraminotomy. Semin Spine Surg 26 : 148-153, 2014
21. van Eck CF, Regan C, Donaldson WF, Kang JD, Lee JY : The revision rate and occurrence of adjacent segment disease after anterior cervical discectomy and fusion: a study of 672 consecutive patients. Spine (Phila Pa 1976) 39 : 2143-2147, 2014

22. Wang F, Wang P, Miao DC, Du W, Shen Y : Different surgical approaches for the treatment of adjacent segment diseases after anterior cervical fusion: a retrospective study of 49 patients. Medicine (Baltimore) 96 : e7042, 2017

23. Zdeblick TA, Zou D, Warden KE, McCabe R, Kunz D, Vanderby R : Cervical stability after foraminotomy. A biomechanical in vitro analysis. J Bone Joint Surg Am 74 : 22-27, 1992 